\title{
Is ginger (Zingiber officinale) mouthwash a convenient therapeutic for denture stomatitis?
}

Hosein Eslami ${ }^{1}$, Solmaz Pakroo ${ }^{2}$, Taher Entezari Maleki ${ }^{3}$, Nazila Sadeghi $^{2}$, Vahid Fakhrzadeh ${ }^{4 *}$

1. Dental and Periodontal Research Center, Department of Oral and Maxillofacial Medicine, Tabriz University of Medical Sciences, Tabriz, Iran

2. Dental and Periodontal Research Center, Student of Dentistry, Tabriz University of Medical Sciences, Tabriz, Iran

3. Drug Applied Research Center, Department of Clinical Pharmacy, Tabriz University of Medical Sciences, Tabriz, Iran

4. Dental and Periodontal Research Center, Department of Prosthodontics, Tabriz University of Medical Sciences,

Tabriz, Iran

\begin{abstract}
Introduction: Denture stomatitis is the most common type of chronic oral candidiasis. Ginger (Zingiber officinale) is an herbal plant with profound antioxidant, antibacterial, anti-inflammatory and antifungal effects with possible effects on Candida albicans. In this study, we aimed at comparing the efficacy of ginger and nystatin mouthwashes on denture stomatitis.

Materials and Methods: In this randomized clinical trial, 30 patients with type II denture stomatitis were randomly assigned into two groups. Group 1 received ginger mouthwash $(20 \mathrm{ml}, 3$ times a day for 20 days), while group 2 used nystatin mouthwash (500000 IU, 3 times a day for 20 days). The patients were visited on days $5,10,15,20$. In each follow-up visit, the length and width of erythema were measured using a digital caliper. Patients' satisfaction with the treatment was evaluated at the end of the study.

Results: During a 20-day treatment period, both treatments significantly reduced the width and length of the erythema $(P<0.001)$; but the changes between groups were not significant $(P=0.9$ for both measurements). Patients receiving ginger mouthwash were significantly more satisfied with the outcome compared to those receiving nystatin mouthwash $(86.7 \%$ vs. $13.3 \%, P<0.001)$.

Conclusion: Although both mouthwashes have acceptable efficacy on denture stomatitis, patients were more satisfied with ginger use. Therefore, ginger mouthwash is recommended as an alternative to nystatin mouthwash in treatment of denture stomatitis.
\end{abstract}

Keywords: Denture stomatitis; Ginger; Nystatin; Mouthwash

\section{Corresponding author:}

Vahid Fakhrzadeh

Dental and Periodontal Research Center, Department of Prosthodontics, Tabriz University of Medical Sciences, Tabriz, Iran

Zip code: 5166618573 E-mail: eslamihosein56@yahoo.com

Receive date: 2015-03-17| Accept date: 2013-04-25| Publish date: 2015-05-03

DOI: 10.7575/aiac.abcmed.15.03.03.04 


\section{Introduction}

Denture stomatitis (DS) is a chronic inflammation of mucous membrane supporting the movable prostheses and is the most common type of chronic oral candidiasis. This inflammation is accompanied with erythema, swelling of mucous membrane, and occasionally with pain and burning (1-3).

Although etiology of DS is multifactorial, poor denture hygiene, pathogenic Candida infection, and repeated use of dentures are the predominant etiological factors (3). The denture produces a favorable environment for microorganism growth and Candida albicans is the most important organism in the pathogenesis of DS (4-6).

Current treatment includes control of denture plaque, some rest periods of denture wearing in addition to the use of antimicrobial agents $(7,8)$. Topical antifungal drugs, such as nystatin, amphotericin $B$, and miconazole as well as systemic fluconazole are the therapeutic choice for DS (9-13). However, clinical relapse and recurrence after therapy are high (11-14) and there is no uniform treatment protocol for all patients $(15,16)$.

Along with the high relapse and recurrence rates, some drugs have complications that reduce patient compliance. As for nystatin, bitter taste, possible hypersensitivity reaction, diarrhea, vomiting and stomach pain may reduce its efficacy $(17,18)$. Therefore, it is important to find natural effective antifungal compounds with less adverse side effects.

Ginger (Zingiber officinale) is used in traditional medicine for the treatment of many diseases such as inflammation, morning sickness in pregnancy and many infectious diseases (19-21). It is shown that ginger extracts have profound anti-oxidant, antibacterial, anti-inflammatory and antifungal effects (22). Their effects on C. albicans in an in vitro study and their utility in dental disease have been previously reported $(23,24)$; but a little is known about its role on the treatment of DS.

In this study, we aimed to evaluate utility and efficacy of ginger mouthwash in comparison to nystatin mouthwash in the treatment of DS.

\section{Materials and methods}

In this randomized double-blind clinical trial, 30 patients with DS visiting Tabriz University Dentistry clinics in 2014 were recruited. Patients with erythematosus DS, masticatory muscle health (found on the clinical examination of the masticatory muscles with no tenderness and trismus), denture fit (no signs of loose discoloration), ability to use mouthwash, and with mental health were included. Patients with history of using antifungal drugs, antibiotics, and corticosteroid within the previous month, allergy to ginger and nystatin mouthwashes, immunodeficiency, Alzheimer's disease, chewing muscle disorder, psychological disorders, and inability to use a mouthwash were excluded. Those with a ginger-rich diet, and loose and discolored dentures were excluded as well. The Ethics Committee of the Tabriz University of Medical Sciences approved the study and all patients gave informed consent. The trial was conducted in accordance with the guidelines of the Declaration of Helsinki.

Patients entered the study following clinical examination, confirmation of DS by the oral medicine specialist, and filling an informed consent form. The information regarding the age, gender, length of denture use, denture use during sleep, denture cleansing method, and also daily number of cleansing occasions was recorded. 
Using a computer generated table of random numbers, the subjects were randomly assigned to receiving ginger mouthwash (group I) or nystatin mouthwash (group II) each comprising 15 patients. Two groups were similar with regard to the grade of DS. Group I were instructed to rinse with $20 \mathrm{ml}$ of ginger mouthwash (Rozhin Co., Tabriz, Iran), while group II used 500000 IU of nystatin mouthwash (Jaber-ebne-Hayan Co., Tehran, Iran). Both groups used mouthwash 3 times a day for a period of 20 days. The patients were advised to swish mouthwash for 1 minute and avoid eating and drinking for 30 minutes afterwards. Ginger and nystatin mouthwash bottles were in an identical shape and the patients or the researcher evaluating the outcome was unaware of the drug. The length and width of the erythema was measured during the followup visits at days $0,5,10,15$ and 20 of the study.

Patients' satisfaction with the treatment was measured using a 4-point Likert scale question. Responses ranged from 1 (poor) to 4 (very good). Then the satisfaction scale was dichotomized to $0=$ Not Satisfied (consisting of poor and fair responses), and 1=Satisfied (consisting of good and very good responses).

The data were presented as mean \pm stan-dard deviation or percentages. All the statistical analyses were performed using SPSS statistical software version 15.0 (SPSS Inc., Chicago, IL, USA). The values were compared between groups using the independent t-test. Categorical data were compared using Chisquare test, or the Fisher's exact test. Repeated measure of ANOVA was used to compare serial changes in length and width of erythema between groups. A $P$ value $<0.05$ was considered statistically significant.

\section{Results}

Table 1 shows the baseline characteristics between two studied groups. There was no significant difference between groups in age and findings related to denture use and cleansing $(P>0.05)$.

The changes in length and width of erythema in different evaluation periods between groups are demonstrated in Table 2 . Using repeated measure of ANOVA, we observed that during a 20-day treatment period, both treatments significantly reduced the width and length of the erythema $(P<0.001)$; but the changes between groups were not statistically significant $(P=0.9$ for both measurements).

Table 3 demonstrates patients' satisfaction with the treatments. Most cases in the ginger group reported good and very good satisfaction, while most cases in the nystatin group reported poor and fair satisfaction. Using the satisfaction scale, we observed that patients receiving ginger mouthwash were significantly more satisfied with the outcome compared to those receiving nystatin mouthwash ( $86.7 \%$ vs. $13.3 \%, \mathrm{P}<0.001)$.

\section{Discussion}

Infectious factors including Candida spp. mainly $C$. albicans are among the main causes of DS $(25,26)$. Systemic or local administration of antifungal drugs mainly nystatin and fluconazole are the common treatments for DS. However, toxicity and resistance to normally used antifungal drugs is a complicated challenge. Recently, application of herbal plants for treatment of DS has gained a world-wide popularity (27).

Ginger and its extracts are among herbal plants used for the treatment of DS. Along with reported antifungal and antibacterial properties (28), an inhibitory effect of ginger extracts on C. albicans has been reported both in vitro and vaginal candidiasis $(29,30)$. Nevertheless, little is known about the efficacy of ginger ingredients in oral cavity diseases. 


\begin{tabular}{|c|c|c|c|c|}
\hline \multicolumn{2}{|c|}{ Age (years) } & $62.5 \pm 9.1$ & $62 \pm 11.3$ & 0.62 \\
\hline \multicolumn{2}{|c|}{ Duration of denture use (years) } & $7.5 \pm 2.7$ & $8.3 \pm 6.3$ & 0.52 \\
\hline \multicolumn{2}{|c|}{ Denture use at night } & $4(26.7 \%)$ & $3(20 \%)$ & 0.65 \\
\hline Cleansing time per & No cleansing & $2(13.3 \%)$ & 0 & NA \\
\hline \multirow[t]{3}{*}{ day } & Once & $6(40 \%)$ & $7(46.7 \%)$ & \\
\hline & Twice & $3(20 \%)$ & $3(20 \%)$ & \\
\hline & Three times & $4(26.7 \%)$ & $5(33.3 \%)$ & \\
\hline \multirow[t]{3}{*}{ How to cleanse } & Water & $2(13.3 \%)$ & $2(13.3 \%)$ & NA \\
\hline & Water and soap & $2(13.3 \%)$ & $2(13.3 \%)$ & \\
\hline & Water and brush & 9 (60.1\%) & $11(73.35)$ & \\
\hline
\end{tabular}

NA: Not Applicable

Table 1: Baseline characteristics between two groups

In the present study, we assessed the efficacy of ginger mouthwash compared to nystatin mouthwash on DS. Our findings revealed that the efficacy of both treatments on improving the erythema in DS was similar in a 20-day treatment period. In the study of ALSumaidae, the antifungal properties of some natural oils (sunflower, sesame, nigella sativa, flax, and ginger oils) in relation to nystatin suspension on acrylic resin denture base materials were evaluated and the results showed that natural oils were effective antifungal agents (31).

It is shown that nystatin is effective in reducing Candida oral colonization and treatment of DS. Nystatin reduces the growth and multiplication of fungal cells and the adherence capacity of Candida to the epithelial

cells and denture surfaces through altering the membrane permeability $(32,33)$. However, nystatin has some disadvantages such as unpleasant taste (34) and possible gastrointestinal symptoms including diarrhea and vomiting $(17,18)$ that may decrease the patient's compliance.

Similarly, recent studies have shown that ginger has broad anti-bacterial activity in particular the inhibitory effects against C. albicans (21,35,36). Moreover, it has gastroprotective and antiemetic effects and does not accompany with significant side effects which are usually reported by other antifungal agents such as nystatin (22). Likewise, in the present study we observed that patients were more satisfied with ginger mouthwash rather than the nystatin mouthwash. 


\begin{tabular}{ccccccc}
\hline Variable & Group & Day 0 & Day 5 & Day 10 & Day 15 & Day 20 \\
\hline Length & Nystatin & $26.28 \pm 6.24$ & $22.63 \pm 6.88$ & $17.53 \pm 7.50$ & $6.34 \pm 10.18$ & $4.02 \pm 10.60$ \\
& Ginger & $26.22 \pm 5.70$ & $22.91 \pm 5.54$ & $17.73 \pm 4.71$ & $8.55 \pm 3.75$ & $1.16 \pm 1.77$ \\
& & & & & & \\
Width & Nystatin & $31.06 \pm 9.01$ & $27.22 \pm 6.82$ & $21.92 \pm 7.21$ & $7.60 \pm 11.32$ & $4.49 \pm 11.56$ \\
& Ginger & $32.20 \pm 4.37$ & $28.81 \pm 4.35$ & $20.32 \pm 5.10$ & $10.49 \pm 3.79$ & $1.28 \pm 2.02$ \\
\hline
\end{tabular}

Table 2: Length and width of erythema in different evaluation periods between groups

\section{Satisfaction}

\begin{tabular}{ccccc} 
& Poor & Fair & Good & Very good \\
\hline Ginger group & 0 & $2(13.3 \%)$ & $3(20 \%)$ & $10(66.7 \%)$ \\
Nystatin group & $6(40 \%)$ & $7(46.7 \%)$ & $2(13.3 \%)$ & 0
\end{tabular}

Table 3: Patients' satisfaction with both treatments

In conclusion, it seems that both ginger and nystatin mouthwashes have acceptable and similar efficacy on treatment of DS, but patients are more satisfied with ginger mouthwash rather than the nystatin mouthwash due to fewer side effects. Therefore, ginger mouthwash is recommended as an alternative to nystatin mouthwash in treatment of DS.

\section{Acknowledgments}

The authors would like to appreciate the Research Deputy of Tabriz University of Medical Sciences for financial support of the present study. We would like to thank Rozhin Co. management who helped us with preparation of the ginger mouthwash.

\section{Competing interests}

The authors declare no conflicts of interest.

\section{References}

1. Al-Dwairi ZN. Prevalence and risk factors associated with denture-related stomatitis in healthy subjects attending a dental teaching hospital in North Jordan. J Ir Dent Assoc. 2008;54(2):80-3.

2. Salerno C, Pascale M, Contaldo M, Esposito V, Busciolano M, Milillo L, et al. Candida-associated denture stomatitis. Med Oral Patol Oral Cir Bucal. 2011;16:139-43.

3. Gendreau L, Loewy ZG. Epidemiology and etiology of denture stomatitis. J Prosthodont. 2011;20(4):251-60. 
4. Jean B, Jean PG, Louis de K, Sylvie LA, Benoit L, Pierre R. Reassessing the presence of Candida albicans in denturerelated stomatitis. Oral Surg Oral Med Oral Pathol Oral Radiol Endod. 2003;95:51-59.

5. Webb BC, Thomas CJ, Willcox MD, Harty DW, Knox KW. Candida-associated denture stomatitis. Aetiology and management: a review. Part 3. Treatment of oral candidosis. Aust Dent J. 1998;43:244-249.

6. Bilhan H, Sulun T, Erkose G, Kurt H, Erturan Z, Kutay O, et al. The role of Candida albicans hyphae and Lactobacillus in denture-related stomatitis. Clin Oral Investig. 2009;13(4):363-8.

7. Iacopino AM, Wathen WF. Oral candidal infection and denture stomatitis: A comprehensive review. J Am Dent Assoc. 1992;123:46-51.

8. Shay K, Truhlar MR, Renner RP. Oropharyngeal candidosis in the older patient. J Am Geriatr Soc. 1997;45:863-70.

9. Dorocka-Bobkowska B, Konopka K. Susceptibility of candida isolates from denture-related stomatitis to antifungal agents in vitro. Int J Prosthodont. 2007;20:504-6.

10. Martinez-Beneyto Y, Lopez-Jornet $P$, Velandrino-Nicolas A, Jornet-Garcia V. Use of antifungal agents for oral candidiasis: Results of a national survey. Int J Dent Hyg. 2010;8:47-52.

11. Bissell V, Felix DH, Wray D. Comparative trial of fluconazole and amphotericin in the treatment of denture stomatitis. Oral Surg Oral Med Oral Pathol. 1993;76:35-9.

12. Martin-Mazuelos E, Aller Al, Romero MJ, Rodriguez Armijo A, Gutierrez MJ, Bernal S, et al. Response to Fluconazole and itraconazole of Candida spp. in denture stomatitis. Mycoses. 1997;40:283-9.

13. Pappas PG, Kauffman CA, Andes D, Benjamin DK Jr, Calandra TF, Edwards JE Jr, et al. Clinical practice guidelines for the management of candidiasis: 2009 update by the Infectious Diseases Society of America. Clin Infect Dis. 2009;48:503-35.

14. Karyotakis NC, Anaissie EL. The new antifungal azoles: Fluconazole and itraconazole. Curr Opin Infect Dis. 1994;7:658-66.

15. Salerno C, Pascale M, Contaldo M, Esposito V, Busciolano M, Milillo L, et al. Candida-associated denture stomatitis. Med Oral Patol Oral Cir Bucal. 2011;16:139-43.

16. Pires FR, Santos EB, Bonan PR, De Almeida OP, Lopes MA. Denture stomatitis and salivary candida in Brazilian edentulous patients. J Oral Rehabil. 2002; 29:1115-9.

17. Sanita PV, Machado AL, Pavarina AC, Massucato EM, Colombo AL, Vergani CE. Microwave denture disinfection versus nystatin in treating patients with well-controlled type 2 diabetes and denture stomatitis: a randomized clinical trial. Int J Prosthodont. 2012;25(3):232-44.

18. Webb BC, Thomas CJ, Willcox MD, Harty DW, Knox KW. Candida-associated denture stomatitis. Aetiology and management: a review. Part 3. Treatment of oral candidosis. Aust Dent J. 1998;43(4):244-9.

19. Bliddal H, Rosetzsky A, Schlichting P, Weidner MS, Andersen LA, Ibfelt HH, et al. A randomized, placebo controlled, cross-over study of ginger extracts and Ibuprofen in osteoarthritis. Osteoarthritis Cartilage. 2000;8(1):9-12.

20. Mahady GB, Pendland SL, Yun GS, Lu ZZ, Stoia A. Ginger (Zingiber officinale Roscoe) and the gingerols inhibit the growth of Cag A+ strains of Helicobacter pylori. Anticancer Res. 2003;23(5A):3699-702.

21. Ficker CE, Smith ML, Susiarti S, Leaman DJ, Irawati C, Arnason JT. Inhibition of human pathogenic fungi by members of Zingiberaceae used by the Kenyah (Indonesian Borneo). J Ethnopharmacol. 2003;85:289-293.

22. Rahmani AH, Shabrmi FM, Aly SM. Active ingredients of ginger as potential candidates in the prevention and treatment of diseases via modulation of biological activities. Int J Physiol Pathophysiol Pharmacol. 2014;6(2):125-36.

23. Giriraju A, Yunus GY. Assessment of antimicrobial potential of $10 \%$ ginger extract against Streptococcus mutans, Candida albicans, and Enterococcus faecalis: an in vitro study. Indian J Dent Res. 2013;24(4):397-400.

24. Shankland WE 2nd. Four common herbs seen in dental practice: properties and potential adverse effects. Cranio. 2009;27(2):118-24. 
25. Figueiral MH, Azul A, Pinto E, Fonseca PA, Branco FM, Scully C. Denture-related stomatitis: identification of aetiological and predisposing factors - a large cohort. J Oral Rehabil. 2007;34:448-55.

26. Budtz-Jorgensen E, Bertram U. Denture stomatitis. I. The etiology in relation to trauma and infection. Acta Odontol Scand. 1970;28(1):71-92.

27. Sabzghabaee A, Shirdare Z, Ebadian B, Aslani A, Ghannadi A. Clinical evaluation of the essential oil of Pelargonium graveolens for the treatment of denture stomatitis. Dent Res J (Isfahan). 2011;8(Suppl 1):S105-8.

28. Park M, Bae J, Lee D. Antibacterial activity of [10]-gingerol and [12]-gingerol isolated from ginger rhizome against periodontal bacteria. Phytother Res. 2008;22(11):1446-9.

29. Atai Z, Atapour M, Mohseni M. Inhibitory effect of ginger extract on Candida albicans. Am J Applied Sci. 2009;6:1067-69.

30. Mohammadi R, Moattar F. Antifungal activity of Zingiber officinale Rosc. essential oil against fluconazole resistant vaginal isolates of Candida albicans. J Med Plants. 2007;6:22-27.

31. Al-Sumaidae RR. Antifungal action of some natural oils on acrylic resin denture base materials. Al-Rafidain Dent J. 2012;12(2):295-300.

32. Ellepola AN, Panagoda GJ, Samaranayake LP. Adhesion of oral Candida species to human buccal epithelial cells following brief exposure to nystatin. Oral Microbiol Immunol. 1999;14:358-63.

33. Ellepola AN, Samaranayake LP. Adhesion of oral Candida albicans isolates to denture acrylic following limited exposure to antifungal agents. Arch Oral Biol. 1998;12:999-1007.

34. Blomgren J, Berggren U, Jontell M. Fluconazole versus nystatin in the treatment of oral candidosis. Acta Odontol Scand. 1998;56:202-5.

35. Chen IN, Chang CC, Ng CC, Wang CY, Shyu YT, Chang TL. Antioxidant and antimicrobial activity of Zingiberaceae plants in Taiwan. Plant Foods Hum Nutr. 2008;63(1):15-20.

36. Chairgulprasert V, Prasertsongskun S, Wichaporn W. Chemical constituents of the essential oil and antibacterial activity of Zingiber wrayi var. halabala. Songklanakarin J Sci Technol. 2005;27(4):813-8. 